\title{
Paediatric bipolar disorder: international comparisons of hospital discharge rates 2000-2010
}

Joe Clacey, Michael Goldacre and Anthony James

\section{Background}

Controversy surrounds the diagnosis and prevalence of paediatric bipolar disorder, with estimates varying considerably between countries.

\section{Aims}

To determine the international hospital discharge rates for paediatric bipolar disorder compared with all other psychiatric diagnoses.

\section{Method}

We used national data-sets from 2000 to 2010 from England, Australia, New Zealand, the USA and Germany.

\section{Results}

For those aged under 20 years, the discharge rates for paediatric bipolar disorder per 100000 population were: USA 95.6, Australia 11.7, New Zealand 6.3, Germany 1.5 and England 0.9. The most marked divergence in discharge rates was in
5- to 9-year-olds: USA 27, New Zealand 0.22, Australia 0.14, Germany 0.03 and England 0.00 .

\section{Conclusions}

The disparity between US and other discharge rates for paediatric bipolar disorder is markedly greater than the variation for child psychiatric discharge rates overall, and for adult rates of bipolar disorder. This suggests there may be differing diagnostic practices for paediatric bipolar disorder in the USA.

\section{Declaration of interest}

None.

\section{Copyright and usage}

(c) 2015 The Royal College of Psychiatrists. This is an open access article distributed under the terms of the Creative Commons Non-Commercial, No Derivatives (CC BY-NC-ND) licence.
There is considerable controversy regarding the diagnosis of paediatric bipolar disorder, ${ }^{1}$ with some researchers in the USA suggesting that children with severe irritability, mood lability and symptoms of attention-deficit hyperactivity disorder (ADHD), with or without clearly demarcated manic episodes, should be regarded as having paediatric bipolar disorder. ${ }^{2}$ The use of these broader diagnostic criteria would, of course, increase the numbers of cases identified. A meta-analysis of epidemiological surveys cross-nationally using structured diagnostic instruments and standardised criteria found that the rate of narrowly defined paediatric bipolar disorder was $1.8 \%$, with no significant difference between US and non-US studies ${ }^{3}$ including US and English prepubertal patients. ${ }^{4,5}$ However, when using broader diagnostic criteria, including bipolar disorder not otherwise specified, the rates of paediatric bipolar disorder rose to $6.7 \%$ in the USA, which was significantly higher than the $2.4 \%$ reported in other countries. $^{3}$ Reports of the prevalence of paediatric bipolar disorder in clinical settings have found that it has increased markedly in the USA in the past decade. For example, a 40 -fold increase in outpatient visits for paediatric bipolar disorder was reported in the USA over a 10-year period between 1994 and 1995 and between 2002 and $2003 .^{6}$ Similarly, population-adjusted rates of hospital discharges for children with a primary diagnosis of paediatric bipolar disorder increased linearly from 1.3 per 10000 US children in 1996 to 7.3 per 10000 US children in 2004 - a 563\% increase. ${ }^{7}$ A recent study ${ }^{8}$ reported a 72 -fold difference in discharge rates for paediatric bipolar disorder in youth between the USA and England (USA, 100.9 per 100000 population, 95\% confidence interval (CI) 98.1-103.8 v. England, 1.4 per 100000 population, 95\% CI 1.4-1.5). This contrasted with rates for all other child psychiatric diagnoses, which were fourfold higher, and for adults with bipolar disorder which were sevenfold higher, in the USA than in England. This suggests the possibility of differing diagnostic practices between the countries. Older international studies ${ }^{9-12}$ have indicated lower rates of paediatric bipolar disorder in clinical settings in the countries studied. This suggests that substantial differences between countries may be a fairly recent phenomenon. There is a need for up-to-date, comparative international data to place this shift in US practice within a broader international context. We used data collected over an 11-year period to examine the rate and time trends of hospital discharges for paediatric bipolar disorder (including bipolar I disorder, bipolar II disorder, bipolar disorder not otherwise specified and cyclothymia) in the USA, Australia, New Zealand, Germany and England. To our knowledge, this is the first study comparing rates of admission to hospital for paediatric bipolar disorder in the USA $v$. several other countries. We hypothesised that in-patient discharge rates for paediatric bipolar disorder would be higher in the USA than other countries. In addition, we hypothesised that any large cross-national difference in rates would be specific to paediatric bipolar disorder and would not be present in other childhood psychiatric diagnoses or in adult bipolar disorder.

\section{Method}

The methodology for comparing US and English discharge rates for paediatric bipolar disorder has been previously published. ${ }^{8} \mathrm{We}$ extended this methodology as follows.

\section{Study inclusion criteria}

For this study, we selected all in-patient discharges in patients less than 85 years of age between 1 January 2000 and 31 December 2010. Diagnoses were coded using either ICD $-10^{13}$ or ICD $-9^{14}$ depending on the data-set. Using ICD-10, the codes for bipolar disorder were as follows: all bipolar disorders, F31; bipolar I disorder, F31.0-F31.78; bipolar II disorder, F31.8; bipolar disorder 
not otherwise specified, F31.9; and cyclothymia, F34.0. Using ICD-9, the codes were: all bipolar disorders, 296.4-296.8 inclusive; bipolar I disorder, 296.4-296.7; bipolar II disorder, 296.89; bipolar disorder not otherwise specified, 296.67-296.88; and cyclothymia, 301.13 .

\section{Comparison groups}

We extracted data on a broad comparison group of other psychiatric disorders and several specific other diagnoses. For the broad comparison group, the ICD-10 coding was mental disorders (ICD-10, F00-F99), excluding F00-F09, organic conditions; F10-F19, psychoactive substance use; F70-F79, mental retardation; and F31, bipolar disorder.

For ICD-9, the broad comparison group was mental disorders (ICD 290-319), excluding 290-294, organic conditions; 303-305, psychoactive substance use; 310, organic brain damage; 317-319, mental retardation; and 296.4-296.89, bipolar disorders.

We extracted data on single manic episode (ICD-10, F30; ICD-9, 296.00-296.16), unipolar depression (ICD-10, F32-F33; ICD-9, 292.2-292.3, 311), ADHD (ICD-10, F90-90.1; ICD-9, 314.00-314.9) and borderline (emotionally unstable) personality disorder (ICD-10, F60.3; ICD-9, 301.83)

\section{Data-set for US discharge rates}

US data were from the National Hospital Discharge Survey (NHDS) (www.cdc.gov/nchs/nhds.htm), a nationally representative survey of hospital discharges. The sample included 500 hospitals from 2000 to 2007 and 239 hospitals from 2008 to 2010. Military, federal, Department of Veterans Affairs, and prisons were excluded, as was any unit with less than six beds. The anonymous data included demographic details such as age, gender and race. Diagnoses were coded using the ICD-9-CM (Clinical Modification). ${ }^{15}$

As the NHDS is a representative survey $(0.5 \%$ sample), rather than a database including all discharges, it was necessary to adjust the results to provide a national estimate for the USA. The NHDS provides a weight for each discharge, signifying the total number of discharges that one unweighted discharge would represent nationally. Thus, an estimate of the number of discharges for each diagnosis nationally could be calculated by summing the weights for the particular discharge diagnosis, in each year and for each particular age.

\section{Data-set for English discharge rates}

Anonymised statistical records for all National Health Service (NHS) hospital discharges in England, for all specialties, were analysed using the national Hospital Episode Statistics data-set (www.hesonline.nhs.uk). It is coded using ICD-10. The full anonymised data-set was supplied to the Oxford Unit of HealthCare Epidemiology as individual-level records for each hospital admission by the English National Health and Social Care Information Centre. The records were analysed by Oxford Unit staff for this study.

\section{Data-set for German discharge rates}

The German data-set was the Federal Health Monitoring System. Individual institutions are required to report data on all of their discharges to their state statistics office. These data are then pooled by the federal statistics office and summary data published online (www.gbe-bund.de). Diagnostic information is grouped for different age groups covering 5 -year intervals ( $<5$ years, 5-9 years, 10-15 years, etc.), and is coded using ICD-10. The in-patient reporting rate of the hospitals to the statistical offices is about $99.5 \%$, with a proportion of unknown diagnoses of $<0.1 \%$.

\section{Data-set for Australian discharge rates}

The Australian database was the Australian National Hospital Morbidity Database (NHMD; www.aihw.gov.au/hospitals-data/ national-hospital-morbidity-database/). The NHMD is compiled from data supplied by the state and territory health authorities. It is a collection of electronic confidential summary records for separations (episodes of care) in public and private hospitals in Australia. Data are coded using ICD-10-AM (Australian Modification). ${ }^{16}$

\section{Data-set for New Zealand discharge rates}

The New Zealand Database was the New Zealand National Minimum Dataset (Hospital Events) (NMDS; www.health.govt. nz/nz-health-statistics/national-collections-and-surveys/collections/national-minimum-dataset-hospital-events). The NMDS is a national collection of public and private hospital discharge information, including clinical information, for in-patients and day patients. For the study period, only publically funded admissions were available, as the data on privately funded admissions were incomplete. Data were coded using ICD-9 for the year 2000 and ICD-10-AM for 2001-2010.

\section{Statistical analysis}

To calculate hospital discharge rates for paediatric bipolar disorder, we divided the total number of hospital discharges for bipolar disorder in each year of age by the totals of the mid-year population for the same age group over the study period. We also calculated age-specific rates in a similar way, by dividing the total number of discharges for each year of age by the total population of children in 5-year age bands. 95\% confidence intervals countbased discharge rates will be calculated using the Mid-P test. ${ }^{17}$ For US discharge rates, CIs were calculated using a Poisson estimation of the $95 \%$ confidence of the unweighted counts. ${ }^{18}$ The weights used to calculate the discharge rates were then applied to the lower and upper Poisson CIs of the unweighted counts to provide an estimate of the CI of the discharge rate. Rates are given in the Results section. CIs are omitted from the text to avoid visual clutter, but are given in Table 1 .

\section{Ethical approval}

The English NHS Central Office for Research Ethics Committees approved the current work programme of analysis using the English data-set (reference number 04/Q2006/176). The Australian, German, American and New Zealand data-sets are all publicly available anonymised data; therefore, no ethical approval was required for these.

\section{Results}

\section{Discharge rates for BP in children and adults}

Discharge rates for all paediatric bipolar disorder diagnoses combined (i.e. bipolar I disorder, bipolar II disorder, bipolar disorder not otherwise specified and cyclothymia) were significantly higher in the USA compared with other countries studied (Table 1 and Fig. 1). This was particularly the case in the younger age groups (Fig. 3). In the 5-9 age group, the US rate was 27 per 100000 , whereas all other countries had rates of less than 1 per 100000 (Australia 0.14, New Zealand 0.22, England 0.00 and Germany 0.03 ). In the 10-14 age group, the US rate was 134 per 100000 , whereas all other countries had rates of less than 5 (Australia 3.9, New Zealand 1.3, England 0.48 and Germany 0.46). The US rate peaked in the 15-19 age group at 212 per 100000 , which was the highest discharge rate in any country in any age group, the next closest being Australia in the 35-39 age 
Table 1 Discharge rates per 100000 population for the USA, Australia, New Zealand, England and Germany for bipolar disorder and other psychiatric diagnoses, 2000-2010

\begin{tabular}{|c|c|c|c|c|c|c|}
\hline \multirow[b]{2}{*}{ Disorder } & \multirow[b]{2}{*}{$\begin{array}{c}\text { Age range, } \\
\text { years }\end{array}$} & \multicolumn{5}{|c|}{ Rates per 100000 population $(95 \% \mathrm{Cl})$} \\
\hline & & USA & AUS & NZ & ENG & GER \\
\hline \multirow[t]{2}{*}{ All bipolar } & Under 20 & 95.96 (93.36-98.62) & $11.71(11.43-12.00)$ & $6.33(5.91-6.77)$ & $0.93(0.89-0.97)$ & $1.49(1.44-1.55)$ \\
\hline & $20-64$ & $150.63(148.72-152.56)$ & $135.50(134.86-136.15)$ & $75.97(74.92-77.02)$ & $29.77(29.58-29.95)$ & 136.05 (135.76-136.35) \\
\hline \multirow{2}{*}{$\begin{array}{l}\text { Bipolar I } \\
\text { disorder }\end{array}$} & Under 20 & $48.53(46.66-50.46)$ & $6.41(6.20-6.63)$ & $4.02(3.69-4.37)$ & $0.56(0.53-0.60)$ & $1.37(1.32-1.42)$ \\
\hline & $20-64$ & 100.57 (99.87-101.28) & $98.29(97.73-98.84)$ & $54.14(53.26-55.02)$ & $19.07(18.92-19.22)$ & $24.33(24.20-24.46)$ \\
\hline \multirow{2}{*}{$\begin{array}{l}\text { Bipolar II } \\
\text { disorder }\end{array}$} & Under 20 & $5.38(4.79-6.02)$ & $0.62(0.55-0.69)$ & $0.02(0.01-0.06)$ & $0.01(0.00-0.01)$ & $0.07(0.06-0.09)$ \\
\hline & $20-64$ & $11.31(10.78-11.86)$ & $6.28(6.14-6.42)$ & $0.05(0.03-0.09)$ & $0.25(0.23-0.27)$ & $0.44(0.43-0.46)$ \\
\hline \multirow[t]{2}{*}{ Bipolar NOS } & Under 20 & $42.05(40.36-43.80)$ & $4.68(4.50-4.86)$ & $2.29(2.04-2.56)$ & $0.36(0.33-0.39)$ & $0.05(0.04-0.06)$ \\
\hline & $20-64$ & $38.75(37.76-39.75)$ & $30.93(30.62-31.24)$ & $21.78(21.22-22.35)$ & $10.45(10.34-10.56)$ & $0.53(0.51-0.55)$ \\
\hline \multirow[t]{2}{*}{ Cyclothymia } & Under 20 & $0.73(0.61-0.87)$ & $0.05(0.03-0.07)$ & $0.05(0.02-0.11)$ & $0.02(0.01-0.02)$ & $0.07(0.06-0.09)$ \\
\hline & $20-64$ & $0.17(0.12-0.23)$ & $0.50(0.46-0.54)$ & $0.47(0.39-0.55)$ & $0.14(0.13-0.16)$ & $0.32(0.30-0.33)$ \\
\hline \multirow{2}{*}{$\begin{array}{l}\text { Single manic } \\
\text { episode }\end{array}$} & Under 20 & $0.45(0.26-0.70)$ & $1.26(1.16-1.35)$ & $1.18(1.01-1.38)$ & $0.34(0.32-0.37)$ & $0.66(0.63-0.70)$ \\
\hline & $20-64$ & $1.38(1.18-1.60)$ & 7.35 (7.20-7.50) & $5.44(5.16-5.72)$ & $3.59(3.53-3.66)$ & $2.75(2.71-2.79)$ \\
\hline \multirow{2}{*}{$\begin{array}{l}\text { Unipolar } \\
\text { depression }\end{array}$} & Under 20 & $91.82(89.41-94.28)$ & $82.42(81.66-83.19)$ & $31.64(30.69-32.62)$ & $4.83(4.73-4.93)$ & $35.24(34.97-35.50)$ \\
\hline & $20-64$ & 186.36 (184.27-188.47) & 472.35 (471.12-473.54) & 138.56 (137.15-139.98) & $54.72(54.47-54.97)$ & 216.75 (216.37-217.13) \\
\hline \multirow[t]{2}{*}{ ADHD } & Under 20 & $15.82(14.93-16.76)$ & $11.11(10.83-11.39)$ & $10.45(9.91-11.01)$ & $0.84(0.80-0.88)$ & $3.52(3.44-3.60)$ \\
\hline & $20-64$ & $0.66(0.50-0.84)$ & $0.34(0.31-0.37)$ & $5.50(5.23-5.79)$ & $0.06(0.05-0.07)$ & $0.07(0.06-0.07)$ \\
\hline \multirow[b]{2}{*}{$\begin{array}{l}\text { Borderline/ } \\
\text { emotionally } \\
\text { unstable } \\
\text { personality } \\
\text { disorder }\end{array}$} & Under 20 & $0.44(0.30-0.61)$ & 13.38 (13.07-13.69) & $6.62(6.19-7.07)$ & $1.76(1.70-1.82)$ & $0.96(0.92-1.00)$ \\
\hline & $20-64$ & $1.07(0.90-1.26)$ & $46.13(45.75-46.51)$ & 40.75 (39.99-41.52) & $14.44(14.31-14.57)$ & $43.81(43.64-43.98)$ \\
\hline \multirow{2}{*}{$\begin{array}{l}\text { Other } \\
\text { disorders }\end{array}$} & Under 20 & 249.29 (245.42-253.21) & $386.92(385.26-388.57)$ & 299.95 (296.99-302.92) & 44.99 (44.69-45.29) & 423.52 (422.61-424.44) \\
\hline & $20-64$ & 506.81 (503.28-510.35) & 1317.64 (1315.59-1319.69) & 892.61 (889.05-896.19) & 218.75 (218.25-219.25) & 712.06 (711.39-712.73) \\
\hline
\end{tabular}

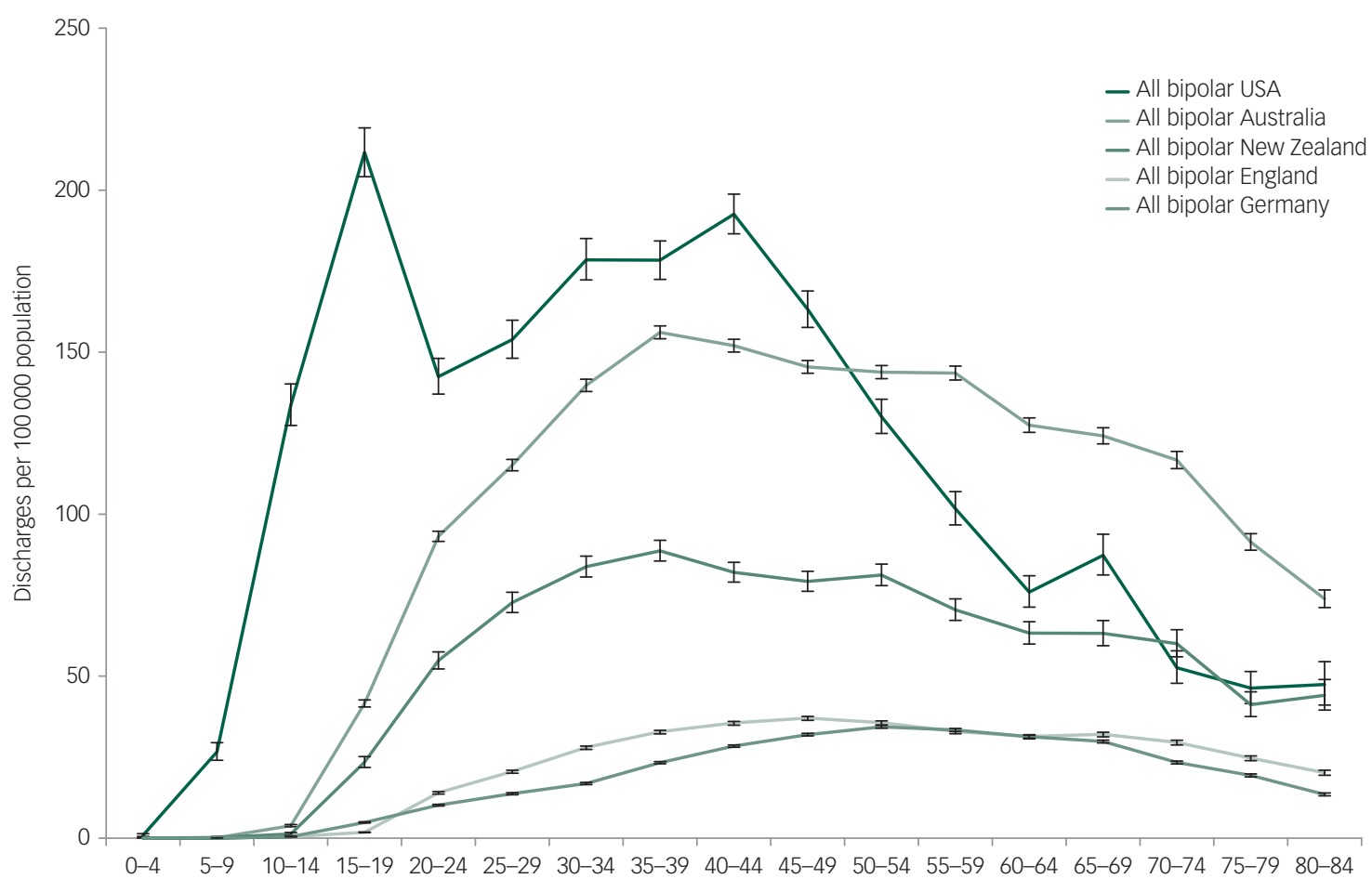

Age group, years

Fig. 1. All bipolar disorder discharges per 100000 population for patients aged 0-84 in the USA, Australia, New Zealand, England and Germany, 2000-2010 


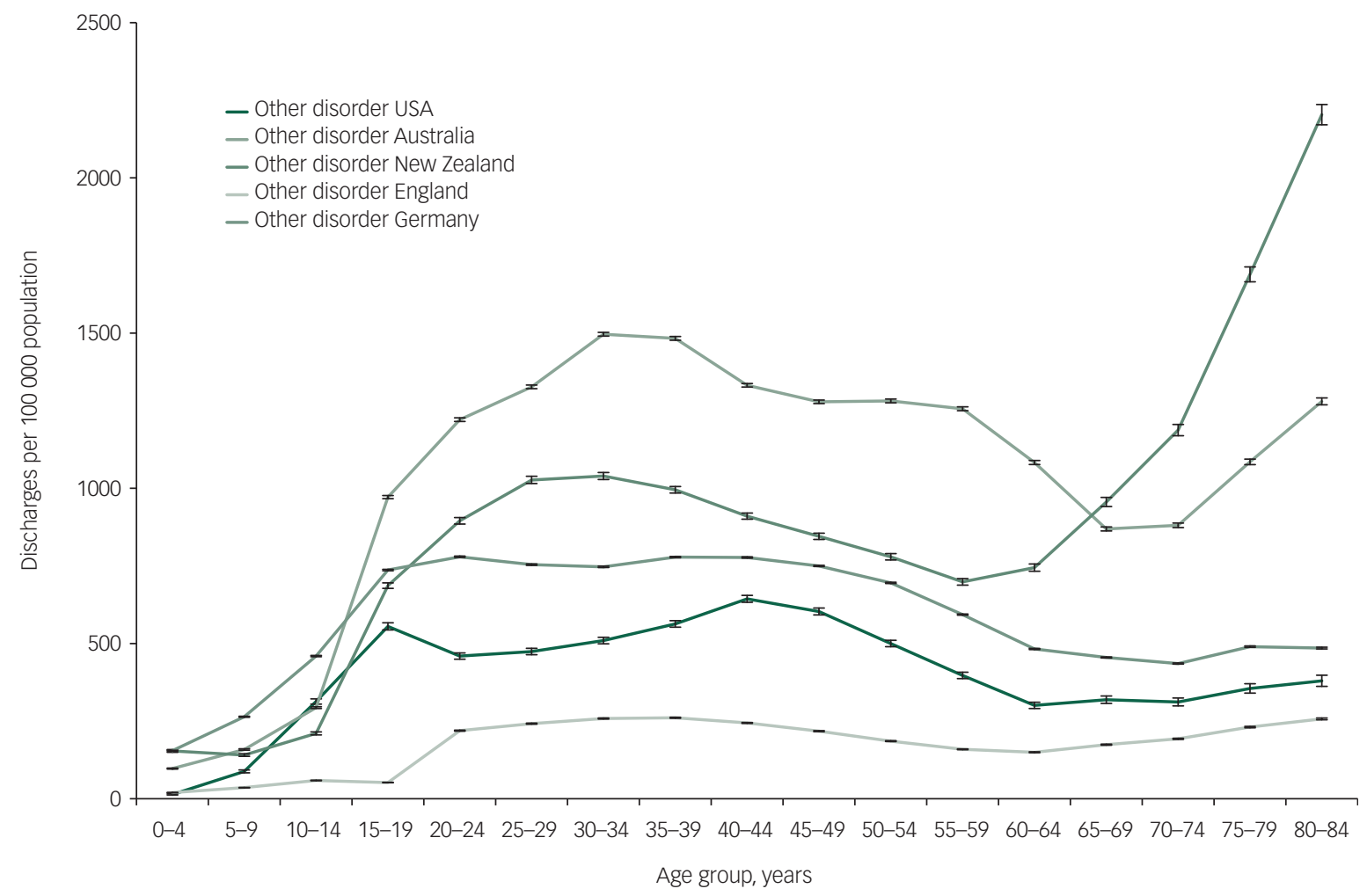

Fig. 2. All other psychiatric disorder discharges (excluding bipolar disorder, organic disorders, mental retardation and substance misuse) per 100000 population for patients aged 0-84 in the USA, Australia, New Zealand, England and Germany, 2000-2010.

group (156). This peak in the US figures was followed by a drop in discharges in the 20-24 age group - a biphasic pattern not seen in any other country.

Likewise, for bipolar I disorder the discharge rate for adolescents was highest in the USA, whereas England had the lowest rate - an 86-fold lower rate than the USA. The USA had a sevenfold higher rate than the next nearest country (Australia). A largely similar overall pattern was seen for bipolar II disorder and including bipolar disorder not otherwise specified.

The discharge rates for bipolar disorder in adulthood show much less divergence. In the age band 20-64, the USA had the highest rate for bipolar I disorder - 151 per 100000 ; the USA being sixfold higher than the lowest (Germany) and 1.1 higher than the next highest (Australia). In fact, for the 50-54 age group, Australia had the highest rate.

The discharge rates for single manic episodes were low and markedly similar across all countries (Table 1), especially for the $0-19$ age range.

\section{Discharge rates for comparison groups}

For the all other psychiatric diagnoses combined, the English discharge rates were low throughout the age range. The US discharge rate in the 15-19 age range is intermediate, with Australia having the highest discharge rate, and the USA having the second lowest rate (Table 1 and Fig. 2). The discharge rate for unipolar depression in adolescence (under 20) were high in the USA (92) and Australia (82), with lower but similar rates in New Zealand (32) and Germany (35), and a much lower rate in England (5). For the adult age group of 20-64, the highest rate was in Australia (472), with England having the lowest rate (54). Only for one disorder - borderline personality disorder - did the USA

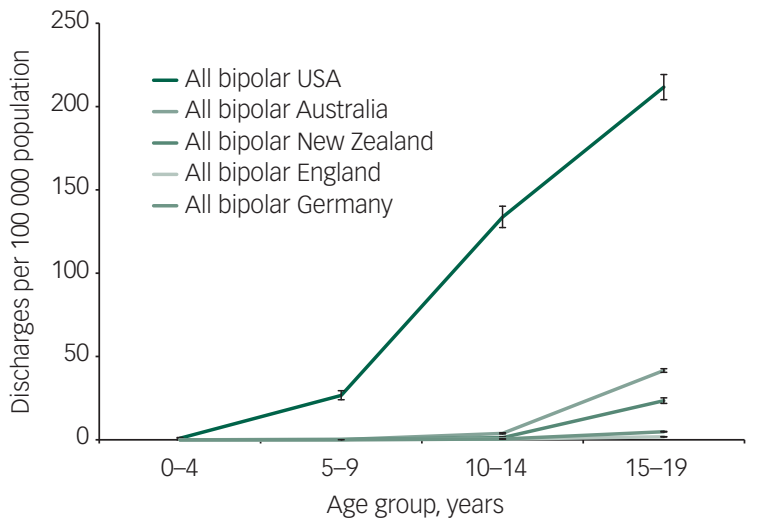

Fig. 3. All bipolar disorder discharges per 100000 population for patients aged 0-19 in the USA, Australia, New Zealand, England and Germany, 2000-2010.

have the lowest discharge rates in adolescence and adulthood in comparison with all countries.

Figs. 1-3 of the international comparisons of age-specific discharge rates for paediatric bipolar disorder show that for all the countries except the USA there were virtually no discharges for paediatric bipolar disorder before the ages of 10-14, whereas in the USA between the ages of 5 and 9 the discharge rate was $27 / 100000$ population. There was a steep rise in the US figures to a peak of 211 discharges per 100000 population by the ages of $15-19$, which then shows an abrupt drop to 142 discharges per 100000 population at ages $20-24$. 


\section{Discussion}

International discharge rates for paediatric bipolar disorder in children and adolescents show very considerable international variation, with the highest rate found in the USA. The overall rate in the USA for those aged under 20 was $95.6 / 100000$ population, which was 8 times higher than Australia, 15 times higher than New Zealand, 64 times higher than Germany and 106 times higher than England. The lowest rates were in England which also had low rates of psychiatric discharges overall.

The pattern of discharges in the USA, with far higher rates of paediatric bipolar disorder in the young than in other countries, needs an attempt at explanation. One possibility is that in the USA paediatric bipolar disorder is more readily diagnosed by inclusion, as suggested by some US researchers, of children with severe irritability, mood lability and symptoms of ADHD, with or without clearly demarcated manic episodes. Furthermore, although there is general agreement on the diagnosis of bipolar I disorder in older adolescents, nevertheless there is a clear peak of discharges for borderline personality disorder around age 15-16 in the USA. ${ }^{8}$ It is possible that in the USA severe adolescent mood lability may be labelled as bipolar disorder. In support of this idea we found that the discharge rate for borderline personality disorder in the USA was very low in this age range, and indeed throughout the age span, compared with that in other countries. Emerging borderline personality disorder is a controversial diagnosis, but it is acknowledged that mood instability is a prominent feature of this diagnosis and it can form a differential diagnosis for bipolar disorder. This study was not designed to examine diagnostic processes, and, therefore, we do not have data to confirm or refute these possibilities. Nevertheless, it is interesting to note that the rates of single manic episodes at discharge, which one might assume may be a plausible alternative diagnosis, are similarly low across all the countries

It is important to examine the trends in discharges for paediatric bipolar disorder in comparison to all other psychiatric discharges. The rates of total psychiatric discharges varies markedly between countries, with Germany having the highest rate of admissions for those aged under 20 years $-424 / 100000$ population - almost 10 times the rate in the country with the lowest rate of discharges (England at 45/100 000 population). Indeed, there appears substantially different child and adolescent psychiatric practices in respect of admission to hospital as evidenced by the overall discharge rates, with, interestingly, the US discharge rate being the second lowest. This highlights the need for comparison of the proportion of paediatric bipolar disorder discharges to total discharges: as calculated from Table 1, this was highest in the USA at 38\%, compared with Australia $3.3 \%$, England 1.6\%, New Zealand 2\% and Germany 0.3\%. Thus, the proportion of paediatric bipolar disorder total psychiatric discharges was over 10 times higher in the USA than Australia and 100 times higher than that in Germany - further evidence of the disproportionately high rate of discharges for paediatric bipolar disorder in the USA.

The trends for discharges for bipolar disorder in adulthood (20-64 years) show greater similarities between countries, although variation is still considerable: the USA had the highest rate $(151 / 100000)$ and England and Germany had the lowest (30 and 26 respectively). The ratio of adulthood (20-64 years) to childhood (under 20) rates for bipolar disorder/paediatric bipolar disorder is also illuminating: it was only $1.6: 1$ in the USA, but much higher in Australia at 11.5:1, New Zealand 12:1, Germany 17:1 and England 33:1. The latter figure, and the generally low rates of paediatric bipolar disorder in England, suggests a possible under-recognition, or underdiagnosis, of paediatric bipolar disorder in England.

There are inevitable limitations to such an epidemiological study, which relies on hospital discharge diagnoses, which are not standardised and therefore open to error. One difference in clinical practice that we have previously examined between US and English hospital care was the length of stay which in England was 5.8 times longer than in the USA (34.5 v. 6 days). ${ }^{8}$ Unfortunately, we could not compare across countries as the data were not readily available. It is very likely that the provision of out-patient care will affect the discharge rate and therefore the length of stay. Further methodological limitations include the use of differing sampling methods. ${ }^{8}$ The US data were collected from a survey, albeit a large survey of more than 500 hospitals initially. This requires that the collected data are scaled up to provide national estimates. Although survey data are open to error on scaling up, any error would have to be selective, since the crossnational differences in discharge rates are different for paediatric bipolar disorder than for other US child in-patient disorders. Of course, we are limited by the ascertainment methods in the studied countries, namely DSM-IV and ICD-10. The limited time period for which data are available means that we are unfortunately not able to comment on any recent changes in practice since the debate on paediatric bipolar disorder has become more prominent. The data that we have available also do not allow us to conduct any analysis into within-country geographical variation, for example, whether paediatric bipolar disorder discharges are limited to an isolated number of centres where particular diagnostic philosophies are prominent, or whether the pattern of discharges represent a national approach to affective instability in young people. If this data were to become available, further research looking into this question would provide strong evidence for this debate.

Studies of geographical variation in healthcare utilisation are now common in many specialties, ${ }^{19,20}$ notably in surgery, but not in psychiatry. Where variation is found, investigators tend to explore whether the variation is warranted (e.g. a result of variation in the incidence of disease or of valid differences in diagnostic criteria) or unwarranted. ${ }^{19}$ Studies of international variation in healthcare in psychiatry are few. The question arises why is there such international variation in discharge rates for paediatric bipolar disorder, even allowing for the overall differences in the total discharge rates between countries, and are they warranted? Although our findings cannot address the factors underlying disparity, it is clear that the discharge rates for paediatric bipolar disorder rates are dramatically lower in European/Australasian areas than the USA. Like the previous EnglandUSA comparative study on hospital discharge rates for paediatric bipolar disorder, ${ }^{8}$ this study relies on administrative prevalence numbers of diagnoses made by healthcare professionals in a defined geographic region over a particular period - rather than a true epidemiological prevalence. Indeed, epidemiological evidence suggests more uniformity in the prevalence of paediatric bipolar disorder. ${ }^{3}$ Variation in diagnostic practice is the most likely explanation. For those countries using the ICD or DSM classification systems, the criteria used to diagnose bipolar disorder differ between ICD-10 and the DSM-IV-TR and DSM-V. 13,21,22 Specifically, ICD-10, which is used more commonly in the UK, requires more than one manic episode for a diagnosis of bipolar disorder, whereas the DSM-IV-TR, and the DSM-5 require only one such episode. Furthermore, the UK National Institute for Health and Care Excellence (NICE) clinical practice guideline ${ }^{23}$ recommends conservative use of the diagnosis of bipolar I disorder in children and adolescents and cautions against making bipolar II disorder diagnoses in this age group, which may influence the cross-national 
differences in the rates of overall paediatric bipolar disorder, bipolar I disorder and bipolar II disorder, but also bipolar disorder not otherwise specified.

There are also cross-national conceptual differences, with some US authorities viewing irritability, not euphoria, as the hallmark symptom of paediatric mania. ${ }^{24}$ Furthermore, in contrast to the episodic nature of adult bipolar disorder, some US authorities maintain that paediatric bipolar disorder is characterised by non-episodic, chronic, ultra-rapid cycling, mixed irritable states. ${ }^{2,25}$ In the UK, such cases would be conceptualised not as paediatric bipolar disorder but as oppositional defiant disorder, conduct disorder and/or ADHD with emotional dysregulation. ${ }^{26}$ In addition, the training and the practice of child psychiatry differs, with evidence from studies using standardised vignettes that US child psychiatrists more readily diagnose paediatric bipolar disorder than English ${ }^{27}$ and likewise, but to a lesser degree, Indian psychiatrists. ${ }^{28}$ Besides these possible clinical issues, the healthcare economy is likely to influence practice, as for instance, with the US system providing incentives for doctors to diagnose and prescribe, and higher reimbursement rates for pharmacological than for psychosocial services. There have also been concerns expressed that trauma, attachment and other psychosocial factors are not properly considered when looking to make diagnoses in young people with affective instability. ${ }^{29}$

These speculative ideas need testing robustly. Meanwhile, it is clear that international discharge rates for paediatric bipolar disorder differ substantially - a finding which we hope could lead to attempts at consensus to allow more uniform clinical practice, and, indeed, research, which at the moment may be hampered by the use of differing diagnostic definitions for this important disorder.

Joe Clacey, BM, BCh BA (Hons), Highfield Unit, Warneford Hospital, Oxford; Michae Goldacre, FFPH, FRCP, BM BCh, BA (Hons), Unit of Health-Care Epidemiology, Nuffield Department of Population Health, University of Oxford, Oxford, UK; Anthony James, MBBS, MRCP, MRCPsych, MPhil, MA (Oxon), Department of Psychiatry, University of Oxford, and Highfield Unit, Warneford Hospital, Oxford, UK

Correspondence: Anthony James, Department of Psychiatry, University of Oxford, Warneford Hospital, Oxford OX3 7JX, UK. Email: anthony.james@psych.ox.ac.uk

First received 10 Jul 2015, final revision 31 Aug 2015, accepted 16 Oct 2015

\section{Acknowledgements}

We thank Nick Hall, Unit of Health-Care Epidemiology, University of Oxford and Roslyn Parke of the New Zealand Ministry of Health Board, for their analytical work on, respectively, the England and New Zealand data-sets.

\section{References}

1 Carlson GA, Meyer SE. Phenomenology and diagnosis of bipolar disorder in children, adolescents, and adults: complexities and developmental issues. Dev Psychopathol 2006; 18: 939-69.

2 Biederman J, Mick E, Faraone SV, Spencer T, Wilens TE, Wozniak J. Pediatric mania: a developmental subtype of bipolar disorder? Biol Psychiatry 2000; 48 458-66.

3 Van Meter AR, Moreira AL, Youngstrom EA. Meta-analysis of epidemiologic studies of pediatric bipolar disorder. J Clin Psychiatry 2011; 72: 1250-6.

4 Costello EJ, Angold A, Burns BJ, Stangl DK, Tweed DL, Erkanli A, et al. The Great Smoky Mountains Study of Youth. Goals, design, methods, and the prevalence of DSM-III-R disorders. Arch Gen Psychiatry 1996; 53: 1129-36.
5 Stringaris A, Baroni A, Haimm C, Brotman M, Lowe CH, Myers F, et al. Pediatric bipolar disorder versus severe mood dysregulation: risk for manic episodes on follow-up. J Am Acad Child Adolesc Psychiatry 2010; 49: 397-405.

6 Moreno $\mathrm{C}$, Laje G, Blanco $\mathrm{C}$, Jiang $\mathrm{H}$, Schmidt $A B$, Olfson $\mathrm{M}$. National trends in the outpatient diagnosis and treatment of bipolar disorder in youth. Arch Gen Psychiatry 2007; 64: 1032-9.

7 Blader JC, Carlson GA. Increased rates of bipolar disorder diagnoses among U.S. child, adolescent, and adult inpatients, 1996-2004. Biol Psychiatry 2007; 62: 107-14.

8 James A, Hoang U, Seagroatt V, Clacey J, Goldacre M, Leibenluft E. A comparison of American and English hospital discharge rates for pediatric bipolar disorder, 2000 to 2010. J Am Acad Child Adolesc Psychiatry 2014; 53: 614-24.

9 Thomsen PH, Moller LL, Dehlholm B, Brask BH. Manic-depressive psychosis in children younger than 15 years: a register-based investigation of 39 cases in Denmark. Acta Psychiatr Scand 1992; 85: 401-6.

10 Reddy YC, Girimaji S, Srinath S. Clinical profile of mania in children and adolescents from the Indian subcontinent. Can J Psychiatry 1997; 42: 841-6.

11 Rasanen $\mathrm{P}$, Tiihonen J, Hakko $\mathrm{H}$. The incidence and onset-age of hospitalized bipolar affective disorder in Finland. J Affect Disord 1998; 48: 63-8.

12 Holtmann M, Duketis E, Poustka L, Zepf FD, Poustka F, Bolte S. Bipolar disorder in children and adolescents in Germany: national trends in the rates of inpatients, 2000-2007. Bipolar Disord 2010; 12: 155-63.

13 World Health Organization. The ICD-10 Classification of Mental and Behavioural Disorders. WHO, 1993.

14 World Health Organization. International Statistical Classification of Diseases and Related Health Problems (ICD-9). WHO, 1978

15 World Health Organization. International Classification of Diseases, Ninth Revision, Clinical Modification (ICD-9-CM). WHO, 2009.

16 National Casemix and Classification Centre. International Statistical Classification of Diseases and Related Health Problems, Tenth Revision, Australian Modification (ICD-10-AM) (8th edn). NCC, 2013.

17 Berry G, Armitage P. Mid-P confidence intervals: a brief review. Stat 1995; 44 417-23.

18 Crow E, Gardener RS. Confidence interval for the expectation of a Poisson variable. Biometrika 1959; 46: 441-53.

19 Wennberg, J. Forty years of unwarranted variation-and still counting. Health Policy 114: 1-2.

20 The Dartmouth Institute for Health Policy and Clinical Practice. The Dartmouth Atlas of Health Care. The Dartmouth Institute for Health Policy and Clinical Practice, 2015. Available at: http://www.dartmouthatlas.org/.

21 American Psychiatric Association. Diagnostic and Statistical Manual of mental Disorders, 5th edn 5th edn (DSM-5). APA, 2013.

22 American Psychiatric Association. Diagnostic and Statistical Manual of Mental Disorders (4th edn) (DSM-IV). 1994.

23 National Institute of Clinical Excellence. Bipolar Disorder: The Assessment and Management of Bipolar Disorder in Adults, Children and Young People in Primary and Secondary Care. NICE, 2014.

24 Wozniak J, Biederman J. Childhood mania: insights into diagnostic and treatment issues. J Assoc Acad Minor Phys 1997; 8: 78-84.

25 Geller B, Tillman R, Bolhofner K, Zimerman B. Child bipolar i disorder: prospective continuity with adult bipolar I disorder; characteristics of second and third episodes; predictors of 8-year outcome. Arch Gen Psychiatry 2008; 65: 1125-33.

26 Sobanski E, Banaschewski T, Asherson P, Buitelaar J, Chen W, Franke B, et al. Emotional lability in children and adolescents with attention deficit/hyperactivity disorder (ADHD): clinical correlates and familial prevalence. J Child Psychol Psychiatry 2010; 51: 915-23.

27 Dubicka B, Carlson GA, Vail A, Harrington R. Prepubertal mania: diagnostic differences between US and UK clinicians. Eur Child Adolesc PSychiatry 2008; 17: 153-61.

28 Mackin $\mathrm{P}$, Targum SD, Kalali A, Rom D, Young AH. Culture and assessment of manic symptoms. Br J Psychiatry 2006; 189: 379-80.

29 Parry PI, Levin EC. Pediatric bipolar disorder in an era of "mindless psychiatry". J Trauma Dissociation 2012: 13:51-68. 